\title{
REACTIONS OF CARBON ATOMS USING CROSSED PULSED MOLECULAR BEAMS
}

Submitted to:

\author{
U.S. Department of Energy \\ Division of Basic Energy Sciences \\ 19901 Germantown, R.L. \\ Germantown, MD 20767
}

Attention: William Kirchhoff

(301) 353-5820

Submitted by: Department of Chemistry

University of Southem Califomia

Los Angeles, CA 90089-0484

Attention: Contracts \& Grants Department

(213) 743-7762

Principal Investigator:

Hanna Reisler

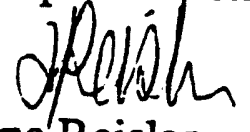

Associate Professor of Chemistry

(213) 743-7852

Approved for the Department:

William Weber

$$
\text { WPP.WN }
$$

Chairman

Department of Chemistry (213) 732-2783
Approved for the University:

Comelius J. Pings

Provost/Vice-President for

Academic Affairs

(213) 743-7762

Date: Counlusf.Puns 


\section{PROGRESS REPORT FOR THE PERIOD 08/88 - 04/89, AND CONTINUATION PROPOSAL FOR YEAR 02.}

In the first eight months of the current funding period, good progress was obtained in three areas:

(a) Developing suitable carbon atom sources;

(b) Building the MPI-TOF mass spectrometer,

(c) Investigating the reactions:

$$
\begin{aligned}
& \mathrm{C}\left({ }^{1} \mathrm{D}\right)+\mathrm{H}_{2} \rightarrow \mathrm{CH}\left(\mathrm{X}^{2} \mathrm{I}\right)+\mathrm{H} \quad \Delta \mathrm{H}=-6.0 \mathrm{kcal}^{\mathrm{mol}} \mathrm{m}^{-1} \\
& \mathrm{C}\left({ }^{1} \mathrm{D}\right)+\mathrm{HCl} \rightarrow \mathrm{CH}\left(\mathrm{X}^{2} \mathrm{M}\right)+\mathrm{Cl} \quad \Delta \mathrm{H}=-7.0 \mathrm{kcal}^{\mathrm{mol}} \mathrm{m}^{-1} \\
& \mathrm{C}\left({ }^{1} \mathrm{D}\right)+\mathrm{HCl} \rightarrow \mathrm{CCl}\left(\mathrm{X}^{2} \mathrm{M}\right)+\mathrm{H} \quad \Delta \mathrm{H}=-5.8 \mathrm{kcal} \cdot \mathrm{mol}^{-1} \\
& \mathrm{C}\left({ }^{3} \mathrm{P}\right)+\mathrm{N}_{2} \mathrm{O} \rightarrow \mathrm{CN}\left(\mathrm{X}^{2} \Sigma\right)+\mathrm{NO}\left(\mathrm{X}^{2} \mathrm{I}\right) \quad \Delta \mathrm{H}=-60.3 \mathrm{kcal}^{\mathrm{m}} \mathrm{mol}^{-1}
\end{aligned}
$$

The development of efficient carbon atom sources was carried out concurrently with studying reactions $1-3$, and we already have intriguing results concerning these reactions, even though the development phase is still in progress. Our goals for the second year are to finish the detailed study of reactions 1-3 including correlatinns between the energy distributions of the fragments, branching ratios, and kinetic e:zergy dependences. These studies will provide prototypical examples of insertion and abstraction reaction dynamics. We also hope to accomplish the deyelopment of laser ablation as a reliable and versatile source of radicals for pulsed mclecular beam studies. Below, we summarize our results on each of these projects and indicate our future plans at the end of each section.

\section{1. $\mathrm{C}\left({ }^{1} \mathrm{D}\right)+\mathrm{H}_{2}$ and $\mathrm{HCl}$}

In these studies, we use $248 \mathrm{~nm}$ photolysis of $\mathrm{C}_{3} \mathrm{O}_{2}$ as the source of $C\left({ }^{1} \mathrm{D}\right)$. This two-photon dissociation process has not yet been investigated in detail, but although the ratio $C\left({ }^{1} D\right): C\left({ }^{3} P\right): C_{2} O$ is unknown, adequate concentrations of $C\left({ }^{1} D\right)$ are produced and the other species do not react with $\mathrm{H}_{2}$ or $\mathrm{HCl}$. We obtain $\mathrm{CH}\left(\mathrm{X}^{2} \Pi\right)$ from reactions 1 and $2 a$, and $\mathrm{CCl}\left(\mathrm{X}^{2} \mathrm{M}\right)$ from reaction $2 \mathrm{~b}$. $\mathrm{CH}\left(\mathrm{X}^{2} \mathrm{M}\right)$ is produced rotationally hot in both reactions, with rotational levels even beyond the thermochemical limit (apparently due to the translational energy of $C\left({ }^{1} D\right)$ ). Such hot rotational populations are typical of reactions proceeding via an insertion mechanism, and are similar to those obtained in reactions of $\mathrm{O}\left({ }^{1} \mathrm{D}\right)$ with $\mathrm{H}_{2}$ and $\mathrm{HCl}{ }^{1,2} \mathrm{CCl}\left(\mathrm{X}^{2} \mathrm{M}\right)$ is identified as the major product of reaction 2 , and we estimate the branching ratio $2 b / 2 a$ at $\sim 7$. This is not surprising, since in an insertion 
reaction the light $\mathrm{H}$ atom is more likely to escape from the $\mathrm{CH}_{2}$ reaction complex than the heavier $\mathrm{Cl}$. CCl is produced rotationally hot, and since its vibrational constants are smaller than those for $\mathrm{CH}$, vibrational excitation is observed as well. In this case, the analysis is complicated by spectral congestion and predissociation in the high rotational and vibrational levels of $\mathrm{CCl}$. We are now exploring ways to overcome the vibrational and rotational predissociation in the upper states of the $\mathrm{CH}$ and $\mathrm{CCl}$ radicals (see below).

The most intriguing results of this study so far are the $\Lambda$-doublet population ratios in the $\mathrm{CH}$ radicals obtained in reactions (1) and (2). By monitoring LIF in the $\mathrm{B}^{2} \Sigma^{-} \leftarrow$ $\mathrm{X}^{2} \Pi$ transition, we find $\Pi\left(\mathrm{A}^{\prime}\right) / \Pi(\mathrm{A}) \sim 1.6 \pm 0.2$ for $\mathrm{J}>2$. This implies that the $\Lambda$ doublet component which is perpendicular to the $\mathrm{CH}$ plane of rotation (i.e., to the intermediate $\mathrm{CH}_{2}$ or $\mathrm{CHCl}$ ) is favored. This result disagrees with Jursich and Wiesenfeld, ${ }^{3}$ who observed $\Pi\left(A^{\prime \prime}\right)<\Pi(A)$ for $J>8$ in the $C\left({ }^{1} D\right)+H_{2}$ reaction. In those studies, $C\left({ }^{1} \mathrm{D}\right)$ was produced by 1 -photon $157 \mathrm{~nm}$ photolysis of $\mathrm{C}_{3} \mathrm{O}_{2}$ and $\mathrm{CH}$ was monitored via the $A^{2} \Delta \leftarrow X^{2} \Pi$ transition, which is much more difficult to analyze with respect to the $\Lambda$-doublet populations (as confirmed in a recent conversation with John Wiesenfeld). So far, all our experimental checks indicate that our result is reproducible and independent of the $C\left({ }^{1} D\right)$ kinetic energy and other experimental conditions (e.g., laser polarization, detector geometry etc.). We are still running some checks, and also plan to reproduce the Comell conditions (i.e., $157 \mathrm{~nm}$ photolysis, $A^{2} \Delta \leftarrow X^{2} \Pi$ detection), before reaching the final conclusion regarding the $\Lambda$-doublet propensities.

We also note that the in-plane $\Lambda$-doublet component is favored in $\mathrm{OH}$ produced via the analogous $\mathrm{O}\left({ }^{1} \mathrm{D}\right)+\mathrm{H}_{2}$ and $\mathrm{HCl}$ reactions, ${ }^{1,2}$ and this is opposite to the trend that we observe with $C\left({ }^{1} D\right)$. However, although both $O\left({ }^{1} D\right)$ and $C\left({ }^{1} D\right)$ reactions proceed by an insertion mechanism, via $\mathrm{H}_{2} \mathrm{O}$ and $\mathrm{CH}_{2}$ intermediates, respectively, there are important differences between the two cases. The $\mathrm{H}_{2} \mathrm{O}$ intermediate has its singlet and triplet surfaces widely separated, and thus surface crossings are unlikely. ${ }^{1}$ Conversely, the $\mathrm{X}^{3} \mathrm{~B}_{1}$ and $a^{1} \mathrm{~A}_{1}$ states of $\mathrm{CH}_{2}$ are separated by only $9 \mathrm{kcal} \mathrm{mol}^{-1}$, and the two states are known to be strongly mixed. In $\mathrm{CH}_{2}\left(\mathrm{X}^{3} \mathrm{D}_{1}\right)$, the $3 \mathrm{a}_{1}$ and $1 \mathrm{~b}_{1}$ orbitals are singly occupied, and the $1 b_{1}$ orbital is nonbonding, and consists mainly of an out-of-plane $p$ orbital centered on the carbon atom. Thus, if reaction (1) proceeds on the triplet surface, it is likely to yield $\mathrm{CH}$ with its $\Pi\left(\mathrm{A}^{\prime \prime}\right) \Lambda$-doublet component favored, as observed in our experiments. 
We are working now quite hard on resolving this issue, and plan to write up the preliminary results for publication in 1-2 months. Since the $\mathrm{CH}_{2}$ potential energy surfaces are well known, we hope that theoretical clalculations will follow suite.

Next year, we plan to complete these studies by doing the following:

(a) Use $157 \mathrm{~nm} \mathrm{C} \mathrm{C}_{2}$ photolysis as a source of $\mathrm{C}\left({ }^{1} \mathrm{D}\right)$;

(b) Establish definitively the $\Lambda$-doublet propensities;

(c) Develop optical diagnostics for $C\left({ }^{1} D\right)$, and obtain its translational energy via its Doppler profiles;

(d) Try to use MPI as diagnostics for $\mathrm{CH}$ and $\mathrm{CCl}$, in order to minimize effects due to predissociation; 4

(e) Complete the analysis of the V,R distributions in $\mathrm{CCl}$;

(f) Ascertain the importance of the singlet and triplet $\mathrm{CH}_{2}$ surfaces in reaction (1).

\section{2. $\mathrm{C}\left({ }^{3} \mathrm{P}\right)+\mathrm{N}_{2} \mathrm{O} \rightarrow \mathrm{CN}\left(\mathrm{X}^{2} \Sigma\right)+\mathrm{NO}\left(\mathrm{X}^{2} \Pi\right)$}

As discussed in our original proposal, this reaction results in high rotational and vibrational levels in the CN product that are easily relaxed, and thus a molecular beam approach is the most suitable for these studies. We produce a beam of carbon atoms by laser ablation of graphite (>90\% C(3P)), and react it with a pulsed free jet of $\mathrm{N}_{2} \mathrm{O}$ seeded in Ar or He. We observe relatively strong CN signals, and have obtained "hotter" V,R distributions than have been hitherto observed. We find, however, that the graphite ablation source, despite being very efficient, is easily 'poisoned' and we intend to construct a rotatable target for the carbon atom source.

The $\mathrm{C}+\mathrm{N}_{2} \mathrm{O}$ reaction will occupy the main part of the second year, and we plan to:

(a) Develop a reliable $\mathrm{C}\left({ }^{3} \mathrm{P}\right)$ laser ablation source. Graphite, carbon fibers and various metal carbides will be tried, and a rotatable-translatable source will be built;

(b) Complete the analysis of the $\mathrm{CN}$ distributions;

(c) Detect the NO product via 2-photon ionization and determine its E,V,R distributions;

(d) Determine correlations between the $\mathrm{CN}$ and NO quantum states via sub-Doppler resolution spectroscopy ;

(e) Develop a model for the reaction dynamics. 


\section{TOF-MPI mass spectrometer}

The dual-pulsed beam machine (built with ARO and NSF funds) is now complete, and we have added (with DOE funding) a home-built MPI-TOF mass spectrometer for product detection and translational energy measurements. This is a differentially pumped chamber with a $1.5 \mathrm{~m}$ long flight tube and microchannel plates for ion detection. We have recently used it to obtain NO MPI signals, and the first application to carbon atom reactions will be the detection of NO from reaction (3).

In the second year we plan to develop the TOF-MPI diagnostics further and use it to determine the translational energies of the reaction products, as described in our original proposal.

\section{REFERENCES:}

1. J.E. Butler, G.M. Jursich, I.A. Watson, and J.R. Wiesenfeld, J. Chem. Phys., 84, 5365 (1986), and references cited therein.

2. E. J. Kruus, B.I. Niefer and J. J. Sloan, J. Chem. Phys., 88, 985 (1988) and references cited therein.

3. G.M. Jursich and J. R. Wiesenfeld, J. Chem. Phys. 83, 910 (1985).

4. J.W. Hudgens, C.S. Dulcey, and G.R. Long, J. Chem. Phys. 87, 4546 (1987). 

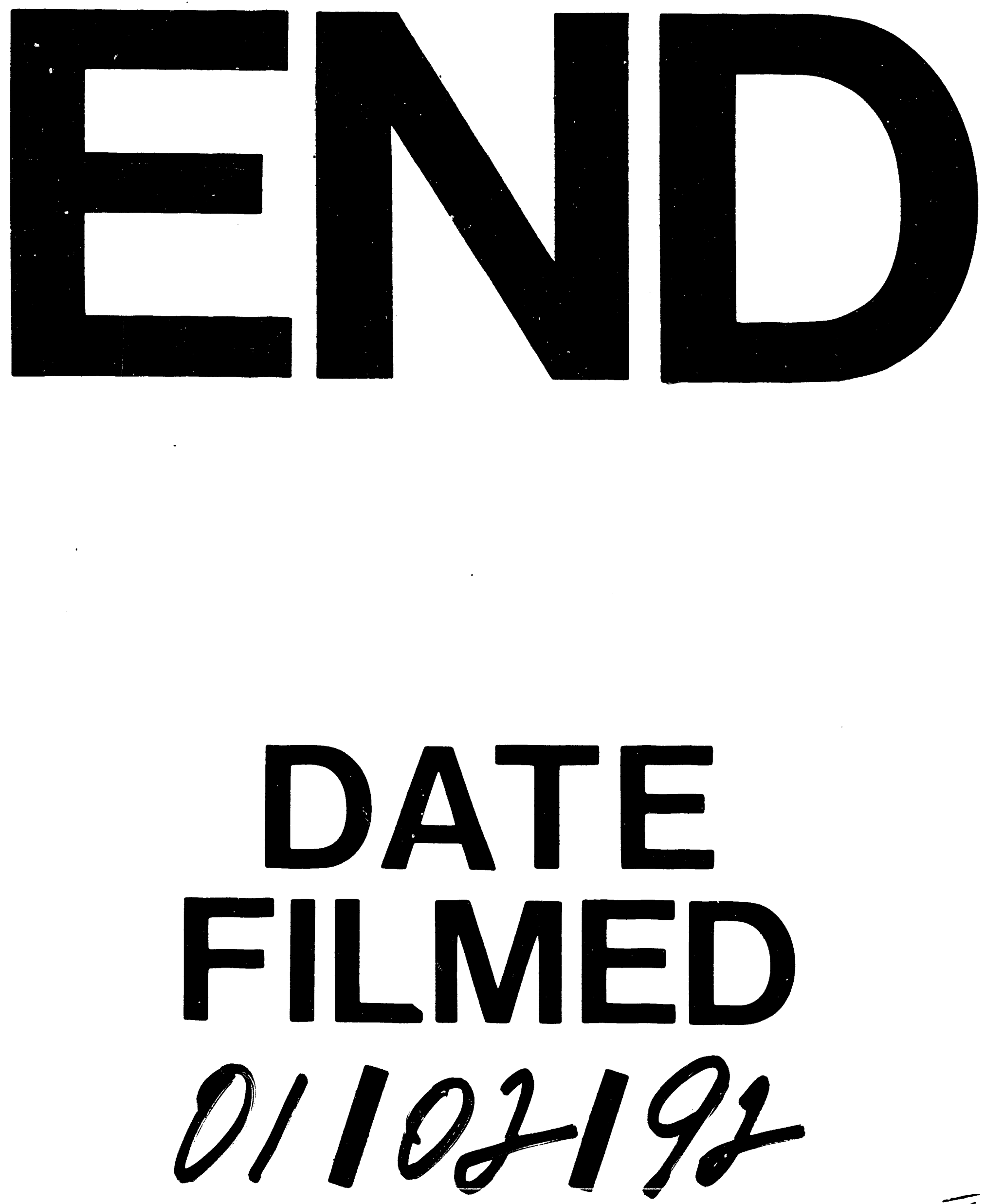
